Research Article

\title{
A Subsidy Strategy to Boost the Activity of Small Milk Producers in Morocco
}

\author{
Ali Labriji $\mathbb{D}$, Youssef El Foutayeni $\mathbb{D}$, and Mostafa Rachik $(\mathbb{D})$
}

Hassan II University of Casablanca, Morocco

Correspondence should be addressed to Youssef El Foutayeni; foutayeni@gmail.com

Received 18 April 2021; Revised 1 September 2021; Accepted 21 September 2021; Published 19 October 2021

Academic Editor: A. Bassam

Copyright (c) 2021 Ali Labriji et al. This is an open access article distributed under the Creative Commons Attribution License, which permits unrestricted use, distribution, and reproduction in any medium, provided the original work is properly cited.

\begin{abstract}
The dairy sector in Morocco is a sector that struggles to develop by facing several difficulties. Therefore, a significant gap has emerged between the main national producers and small farmers, while in the economy, the development of small economic actors presents an important lever of growth. If we assume that the consumer's milk demand function is linear, that it depends only on the consumer's price, and that production costs follow a decreasing return, and finally, by considering only two actors representing the different types of producers, we will show in this paper that a competitive production subsidy of 0.5 MAD can triple the market share of small farmers while being in a situation of Nash-Cournot's equilibrium. In addition, the addition of a subsidy to production costs will reduce the price of milk and, thus, increase the annual milk consumption of Moroccans from 59 liters, which is below the world average consumption, to 94 liters annually, thus benefiting the consumer in addition to small farmers.
\end{abstract}

\section{Introduction}

Since its independence, Morocco has placed the agricultural sector at the center of its development choices given the important economic, social, and territorial issues it raises. This last one has distinguished itself over the decades by its ripple effects on the entire national economy, through its own performance and its interactions with other economic sectors. The proof is, according to the HCP (Haut-Commissariat au Plan is the organization responsible for the production, analysis, and publication of official statistics in Morocco), its weight in the GDP (around 12\%, see [1]) and its status as a provider of jobs for an important tranche of the population (nearly $31.2 \%$ of the employed population, see [2]), as can be seen in Figure 1 (source: HCP, see [2]), without omitting the role of the central sector in certain regions of the Kingdom, in rural areas, for example, where it can reach $74 \%$ of all available jobs.

To support this vital sector, Morocco has launched the Green Morocco Plan (GMP). This plan has the aim of developing and enhancing the agricultural sector in Morocco through several levers and financial aid granted by the State to encourage private agricultural investments that we can list as follows:

(1) Aid for irrigation and land development

(2) Subsidy of the equipment of the exploitation

(3) Supply of certified seeds and subsidy for the creation of new plantations

(4) Promotion and diversification of exports

(5) Support for the genetic improvement of livestock

(6) Subsidy for the creation of units for the valorization of agricultural and dairy production

To learn more about the aid granted under the Green Morocco Plan, see the document produced by the Moroccan Agricultural Development Fund (financial aid from the State to encourage agricultural investment) [3]. Since its launch in 2008 , according to the ADA (the agency for the development of agriculture in Morocco), see [4], the GMP has triggered a structural transformation of the Moroccan agricultural sector. This strategy is on the way to meeting the challenge of 


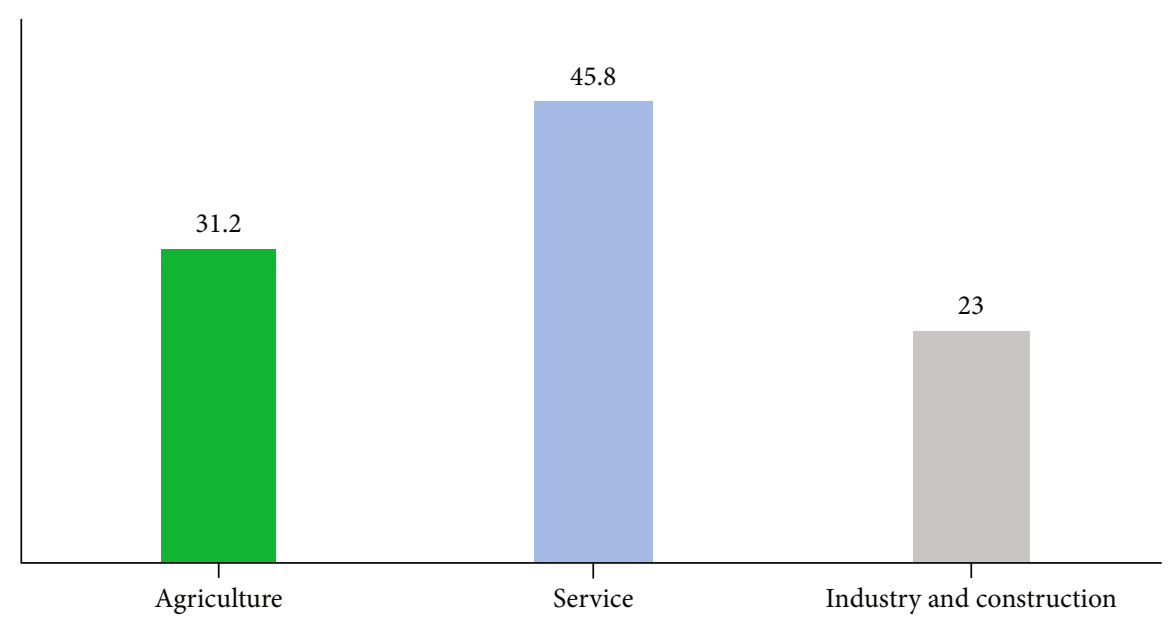

FIGURE 1: Employment structure by sector of economic activity (\%).

strengthening the resilience of agricultural value added by reinforcing the weight of high value-added sectors and improving the productivity of the cereal sector. These achievements were made possible by redirecting public support towards the production of high value-added agricultural products that are perfectly resilient to the vagaries of the weather. The strengthening of public support for the sector has included both public investment and support to private investment in the form of subsidies. Thus, overall public investment at the level of the agricultural sector more than tripled over the 2008-2016 period, from nearly 3.1 billion to 9.9 billion MAD, i.e., an average annual growth rate of nearly $14.4 \%$. The same evolution is observed in the level of the "support to private investment" component, which increased to 3.3 billion over the same period.

According to the DEPF (the direction of studies and financial forecasts in Morocco), see [5], this dynamic has enabled the agricultural sector to achieve sustained and less erratic growth in its added value, with an Average Annual Growth Rate (AAGR) of 6\% over the 2008-2017 period, attesting to the good performance of the various agricultural sectors, particularly the cereal sector whose performance is above average (nearly 80 million quintals). The components of agricultural production other than cereals have recorded a significant rebound, particularly livestock (the 2016 achievement rate of the 2020 target reached $90 \%$ and $68 \%$, respectively, for red and white meats) and arboriculture (the achievement rate of $70 \%$ and $57 \%$, respectively, for citrus fruits and olives).

The sustained growth of the agricultural sector is reflected in the marked decline of the standard deviation of agricultural added value of nearly $63.5 \%$ between the two periods 1990-1999 and 2000-2017, as can be seen in Figure 2 (source: World bank, see [6]).

But, according to the MAPM (the Ministry of Agriculture and Marine Fisheries in Morocco), despite the overall achievements of Morocco in the field of agriculture, the assessment at the level of milk production remains mixed. The dairy industry in Morocco ensures the country's food security by producing $96 \%$ of national needs in milk and derivatives (see [7]). Despite its performance, it faces chal- lenges, particularly related to climate, market stagnation, and farm size. In Morocco, the dairy sector includes nearly 400,000 farms, including 100,000 seasonal farmers. In $2019,2.55$ billion liters of milk were produced, as can be seen in Figure 3 (source: MAPM, see [7]).

The average evolution of milk production remains weak, 4 to $5 \%$ per year. The dairy industry generates a turnover of 13 billion MAD, 7 billion of which are generated by upstream actors in the rural world. A total of 460,000 permanent jobs are provided in addition to several thousand other jobs. Downstream concentrates 2,700 milk collection centers and 82 dairy factories. However, $80 \%$ of the volume is processed by only 10 units, the largest.

The self-sufficiency rate has risen from $88 \%$ in 2008 to $96 \%$ in 2016. Despite this good performance, the dairy industry faces some challenges and is stagnating. First of all, the climatic hazards due to the irregularity of rainfall in Morocco constitute a considerable obstacle to the development of farmers. The second obstacle is the size of the farms, which makes them very sensitive to the difficulties they may face. Morocco has a total of 1.2 million dairy cows distributed among 400,000 farmers, i.e., an average farm size of 3 cows. Despite the objective of increasing this figure to 5 , the trend is rather downward. Indeed, in recent years, the price of inputs has increased in Morocco. This situation has forced smallholders to further reduce the size of their herds. Smaller farms face a problem of profitability because of rising production costs and stagnating milk selling prices. As of today, $90 \%$ of the farms have less than 10 cows (see [8]).

It is therefore easy to see the importance of small producers in the economic landscape, their potential, but also the difficulties they face. For this reason, it seems relevant to us to propose a mathematical modeling that will allow us to obtain a balance that will be more profitable for the small producers while avoiding touching the interests of the main producers of the sector. But before doing so, we must recall some notions of economic modeling.

Economic benefit is defined as the difference between the revenues a company receives and the costs it incurs. The revenues and costs of a business depend on the actions taken by 


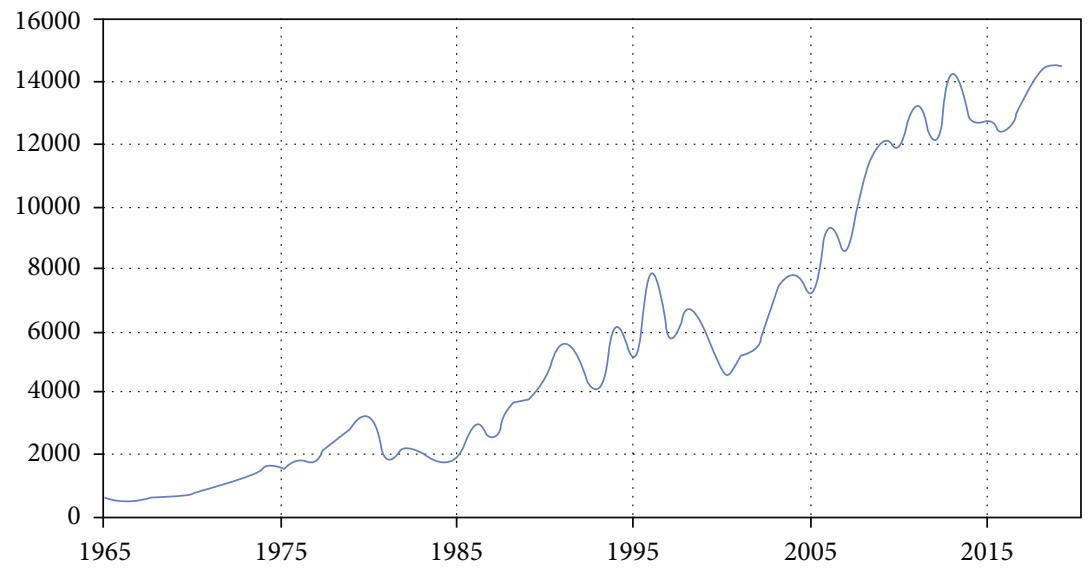

Figure 2: Morocco's agricultural value added in M.USD.

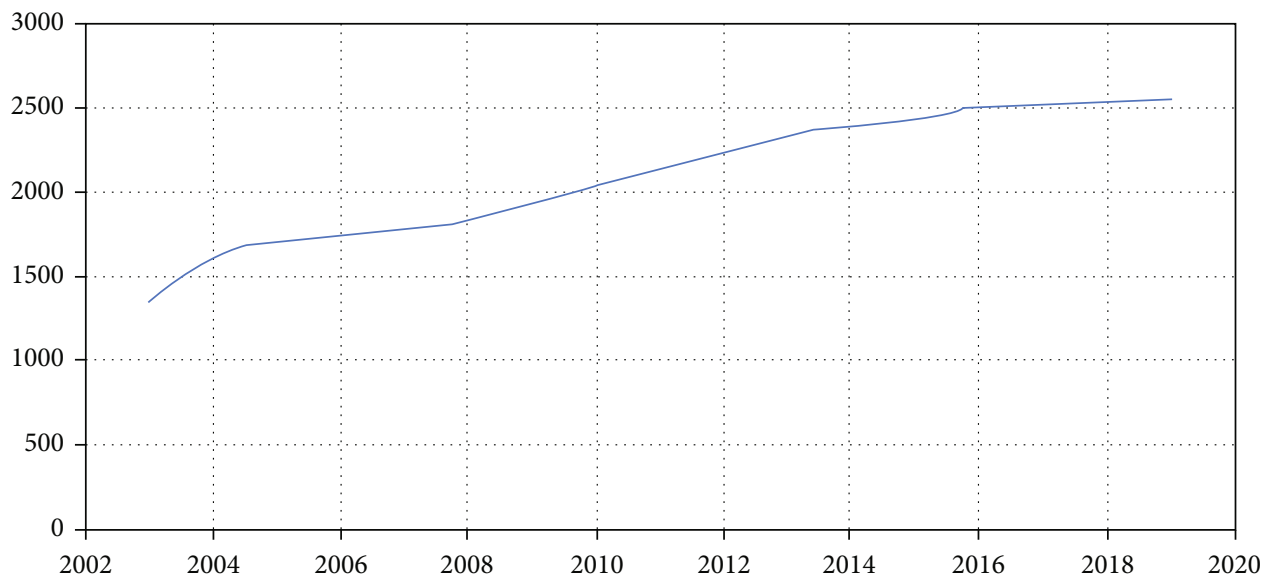

Figure 3: Milk production in millions of liters.

the firm. These actions can take many forms; proper production activities, factor purchases, and advertising purchases are all examples of actions taken by a firm. We can write revenues according to the level of operation of certain $n$ actions, $R\left(a_{1}, \cdots, a_{n}\right)$, and costs according to these same $n$ levels of activity, $C\left(a_{1}, \cdots, a_{n}\right)$. A basic assumption of most economic analyses of firm behavior is that a firm acts in such a way as to maximize its profits, i.e., it chooses actions $\left(a_{1}, \cdots, a_{n}\right)$ in such a way as to maximize $R\left(a_{1}\right.$, $\left.\cdots, a_{n}\right)-C\left(a_{1}, \cdots, a_{n}\right)[9-13]$.

Nevertheless, standard profit maximization studies the optimal decision of a company without taking into consideration the interactions with other competitors. To develop this point, several works have been done based on game theory. The two most frequently used equilibria are the Cournot equilibrium and the Bertrand equilibrium.

In our case, we are mainly interested in the NashCournot equilibrium, mainly because its hypotheses, which we will develop in what follows, correspond to our cases.

Cournot's equilibrium is an economic model used to describe an industrial structure in which firms compete on production volumes. They decide on these volumes independently of each other and at the same time. It is named after Antoine-Augustin Cournot, a mathematician who theorized it by observing the behavior of firms in a duopoly selling spring water. The method of analysis of the system amounts to finding the Nash equilibrium of the game in which two firms simultaneously choose their level of production. This model is based on the following assumptions:

(1) There is more than one company and all companies produce a homogeneous product, so there is no differentiation

(2) Firms do not cooperate; there is no collusion

(3) Firms have market power, so they are price makers. In economics, a price maker refers to a firm's ability to set or influence market prices. This hypothesis is particularly useful to allow us to formulate a direct relationship between the price and the total quantity produced, of the good or service, on the market by all economic actors

(4) The number of firms is fixed, so there is a barrier to entry, in other words, the obstacles that a company must overcome when it wants to enter a new market. Barriers to entry are established by the actors already in place in the sector in question or by regulation. An 
established player in the sector has an interest in ensuring that barriers to entry are kept as high as possible, i.e., that a competitor has difficulty in configuring its organization and accessing specific resources or the necessary distribution channels. On the other hand, it is in the consumer's interest that barriers to entry be low in order to encourage new entrants and stimulate competition

(5) Firms compete on quantities, not prices, and choose their quantities simultaneously

(6) Firms are rational and seek profit maximization

A Nash equilibrium (NE) is a result wherein no player is willing to deviate unilaterally, given the strategies played by other players. In other words, it means that a profile $p^{*}=$ $\left(p_{1}^{*}, \cdots, p_{n}^{*}\right)$ with $p_{i}^{*} \in P_{i}, i=1 \cdots n$ is a Nash equilibrium if no player has an interest in unilaterally deviating from his strategy $p_{i}^{*}$ when other players continue to play the profile $p_{-i}^{*}$. So the Nash-Cournot equilibrium is a Nash equilibrium under the Cournot hypotheses. To learn more about this equilibrium and its different applications, refer to [14-19], and for more information on the computational method in the optimization framework, see [20-26].

Therefore, we can see from the definition of this equilibrium that the small producers of milk from Morocco will have a guaranteed income while guaranteeing the interests of the main national producers. Finding this equilibrium is even more important in light of the current world situation which has caused the bankruptcy of many producers. And so, we are left with a pressing need to find a solution that can improve the situation.

This work will be structured as follows: a first section where we contextualize our work and present the fundamental idea of our research. Then, we will present the foundations of our model as well as its formalization. In the fourth section, we will calculate the equilibrium point of Nash-Cournot as a problem of quadratic complementarity (see [27-29] for more information); in the fifth section, we will perform a simulation assuming the existence of a state subvention as well as its impact on the equilibrium, and finally, we will conclude with a discussion and perspectives for improvement.

\section{Literature Review}

Several studies have examined the issue of dairy production in Morocco, identifying the strategic issues at stake, but also pointing out the different challenges they face. For example, the authors of [30] have drawn a critical picture of the state of dairy production in the Maghreb in general (Algeria, Morocco, and Tunisia) which have begun their policies to support the sector with the aim of achieving food selfsufficiency in the dairy field but which are heading towards a food dependency due to the scarcity of certain essential resources for the development of the industry and more specifically the scarcity of water, given the water stress that weighs on the region, but also, the difficulty to evaluate the remuneration of the farmers which is based only on the quantities supplied and not on the quality of their produc- tion.. In particular, since the current dairy production context is characterized by soaring feed prices and stagnant farm gate milk prices, many farmers argue that milk quality could be an important factor in improving their margins. Realistic support programs targeting small-scale dairy farms must be put at the top of the agricultural policy agenda. In addition, there is a need to evolve the supply and consumption of dairy products, in order to accompany the evolution of the average income of the households, because the latter are mainly satisfied with milk for drinking, while a diversification of the offer as well as of the consumption habits can constitute an important asset for the improvement of the know-how of the women and the increase of their income. Finally, the authors warn of the free trade agreements that are being implemented with the EU and the USA that risk outclassing local production due to the lack of competitiveness. In addition, the authors of [31] have succeeded in highlighting the capacity of evolution and adaptation of the different Moroccan family farms thanks to the characteristics of their farms and the variety of natural, economic, and political changes they have faced during this period, thanks to an observation of a sample of farms over 45 years. In addition, they have also highlighted their capacity to evolve, if the responsible authorities set up statistical studies aimed at getting to know these farmers better and developing strategies and public policies adapted to their needs and situation, especially when competition for access to resources (groundwater, labor, and land) and markets, both between family farms and with local agribusinesses, is a source of uncertainty that weighs on their development dynamics. Another study highlighted the milk production potential of Moroccan farmers [32], diagnosing the major gap between current production and optimal production if technical support was provided to these farmers, adjusting the diet of the cows to the available resources and making it more balanced, but also optimizing the production costs per liter of milk. This would have a direct impact not only on increasing the national milk production but also on reducing the poverty of small producers.

On the other hand, the Nash equilibrium has already been used as a tool for modelling an equilibrium for the dairy market. For example, in [33], the authors showed that the Nash-Cournot equilibrium was the type of equilibrium closest to actual observations in Japan. In [34], the authors used the Nash equilibrium in a game simulation to demonstrate the value of cooperation between different farmers in increasing their milk production and its quality in Tunisia. The same authors demonstrated in [35] the interest of the creation of cooperatives and a healthy mutual aid between the different producers through a Nash equilibrium which showed the increase of the production of the cooperating group of producers.

\section{Mathematical Model}

Let two perfectly substitutable goods be assumed to have the same price. Indeed, in the consumer theory, if the goods have different prices, then the consumer will only buy the cheapest good, whereas if the prices are equal, then the 


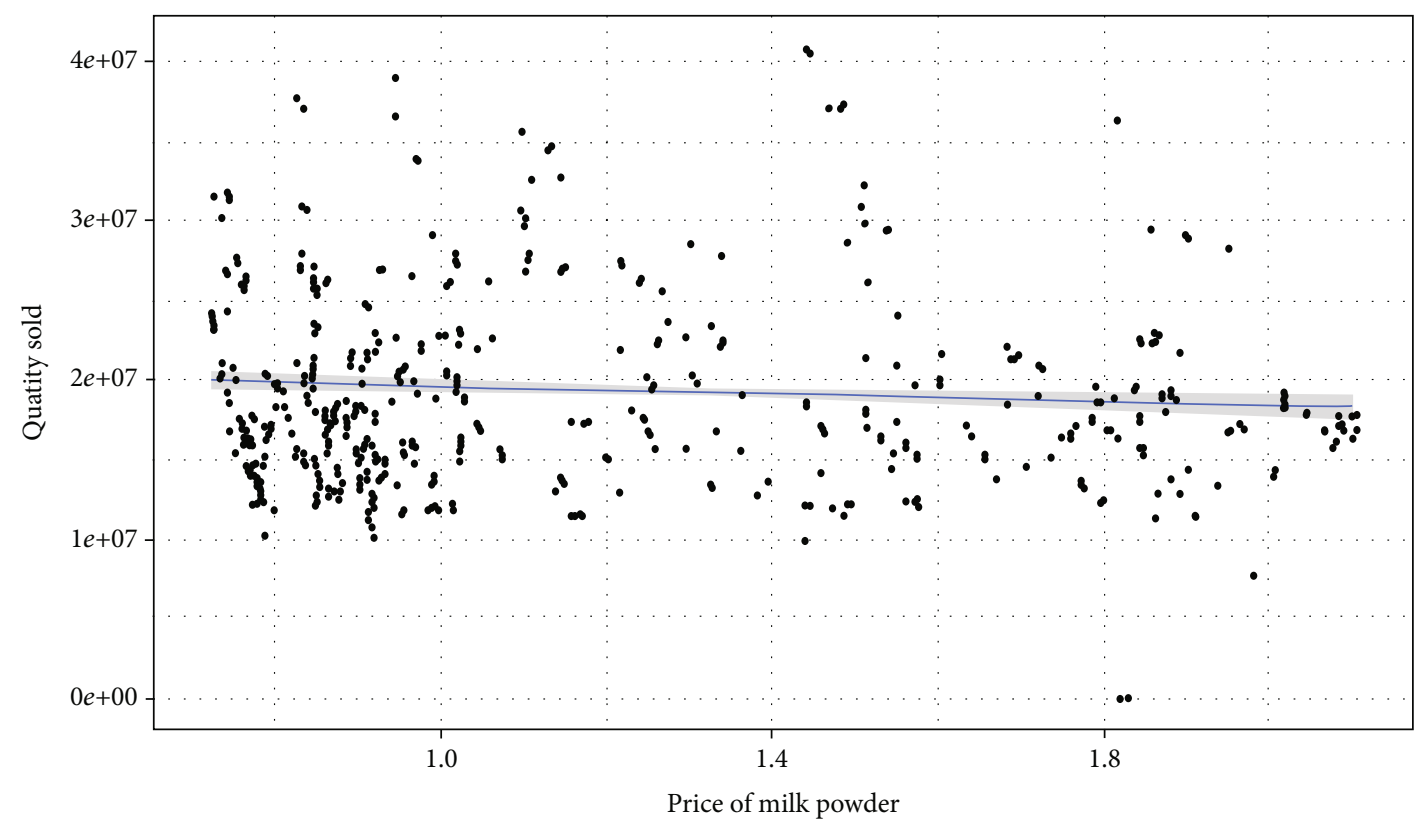

Figure 4: Milk powder demand function.

TABle 1: Estimation of demand function coefficients by linear regression.

\begin{tabular}{lc}
\hline Intercept & 20672306.91 \\
Price of milk powder & -1239109.38 \\
\hline$R^{2}$ & 0.01 \\
Adj. $R^{2}$ & 0.01 \\
Num. obs. & 1410 \\
\hline
\end{tabular}

consumer will divide his consumption indifferently between the two goods. In real life, it is difficult to determine whether buyers choose cheap or expensive goods because the snob effect can lead buyers to choose expensive items (see [11] for more information). So there is a complexity in the buyer's choice. Nevertheless, important results can be achieved without taking individual satisfaction into consideration. So we will proceed according to the classical definitions. The quantity demanded by consumers can be approximated by a function called a demand function in the following form: $q_{d}=d_{0}-d_{1} p$, where $p$ is the price of the product, $q_{d}$ is the quantity demanded, and $d_{0}$ and $d_{1}$ are positive constants, with $d_{0}$ the maximum quantity that the consumer is willing to take even for free and $d_{1}$ the marginal effect of the price increase on the quantity demanded by the consumer; the value of $d_{0}$ can amount to several million units depending on the type of the good. The value of $d_{1}$ also varies according to the type of good; in fact, if it is a commodity of primary necessity, then it can take on small values, for example, bread, which is the basis of a diet. So an increase in the price will have little influence on the consumption of bread. We have chosen to consider a decreasing demand function with respect to the price of milk, because we assume that the Moroccan consumer does not yet have a snob effect, given that milk is a commodity whose national consumption is still very insufficient, given that the country is still in the process of development and has an aver- age GDP per head. As we do not have in Morocco the history of sales in addition to the price, here is an estimation of the demand function of powdered milk at Walmart in the USA shown in Figure 4. The data used can be found in [36].

From Table 1, we can see that the maximum quantity that Walmart customers can absorb is 20,672,307 units and that the price increase of 1 dollar will reduce the quantity requested by $1,239,109$, but we must keep in mind that in reality, the maximum quantity consumed in the USA is much higher than the estimated value because of the limited data, while the value of $d_{1}$ obtained gives us an idea of the behavior of the consumer in the USA.

Now that we have formalized the price behavior, we can define the profit. Let $\pi_{i}$ be the profit of the company $i \in\{1, \cdots$ , $n\}$ defined as follows: $\pi_{i}=\mathrm{CA}_{i}-\mathrm{CT}_{i}$ with $\mathrm{CA}_{i}$ the sales turnover of company $i$ and $\mathrm{CT}_{i}$ the total costs of the same company.

$\mathrm{CA}_{i}$ can be defined as follows: $\mathrm{CA}_{i}=p\left(\sum_{j=1}^{n} q_{j}\right) q_{i}$ with $q_{i}$ the quantity of goods produced by the company $i$. And the price is defined by the inverse function of consumer demand as follows:

$$
p=\frac{d_{0}}{d_{1}}-\frac{\sum_{j=1}^{n} q_{j}}{d_{1}} .
$$

And in order to guarantee a positive price, we put $\sum_{j=1}^{n}$ $q_{j}<d_{0}$.

Since $\mathrm{CA}_{i}=p q_{i}$, then

$$
\mathrm{CA}_{i}=\frac{d_{0}}{d_{1}} q_{i}-\frac{\sum_{j=1}^{n} q_{j}}{d_{1}} q_{i} .
$$

It can also be assumed that both companies have increasing returns. Returns to scale are increasing (law of increasing returns) when output varies more than the 


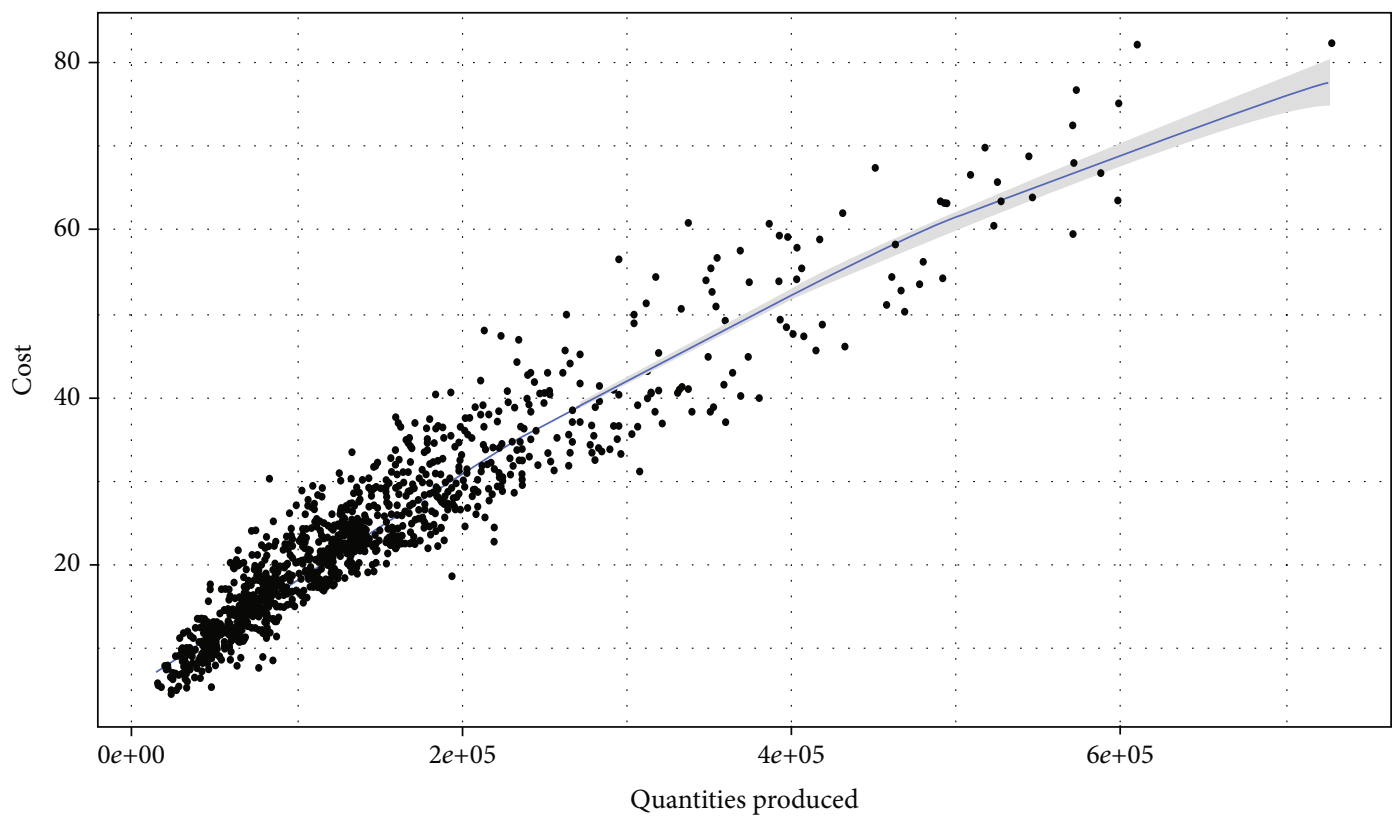

FIgURE 5: The cost function of milk production.

variation in the factors of production used. The production of an additional unit is then accompanied by a decrease in the unit cost, and the same quantity of factors can produce more. This is called an economy of scale. Mathematically, it can be expressed as follows: let $F$ be a production function with $x$ as production factor, then $F(\alpha x)>\alpha F(x)$; we can write the cost function in a quadratic form as follows: $\mathrm{CT}_{i}$ $=c_{0, i}+c_{1, i} q_{i}-c_{2, i} q_{i}^{2} \cdot c_{0, i}$ are the fixed expenses of the company, such as rent, $c_{1, i}$, is the cost of producing one unit of a good, this cost includes all expenses such as the price of raw materials, wages and logistics costs, $c_{2, i}$, is the reduction in costs induced by the increase in production by an additional unit, $-c_{2, i} q_{i}^{2}$, the term is intended to reflect the effect of the economy of scale. For the sake of the illustration, here is the estimation of the cost function of milk production in Figure 5. The data used are those of Spanish Dairy Farm Production, which can be found in [37] and used in [38].

Figure 5 and Table 2 show the quadratic nature of the data, since we cannot accept the null hypothesis of the coefficient associated with the milk production square in the regression analysis (the $p$ values associated with the milk production and its square are less than 0.01 and therefore are significant).

In addition, we will add a term $s_{i}$ which will serve as an indicator of state subsidy for competition and can vary according to the characteristics of the producer. Thus, the cost function can be written as follows:

$$
\mathrm{CT}_{i}=c_{0, i}+c_{1, i} q_{i}-c_{2, i} q_{i}^{2}-s_{i} \sum_{j=1}^{n} q_{j \neq i} .
$$

Therefore, we have

$$
\pi_{i}=\frac{d_{0}}{d_{1}} q_{i}-\frac{\sum_{j=1}^{n} q_{j}}{d_{1}} q_{i}-c_{0, i}-c_{1, i} q_{i}+c_{2, i} q_{i}^{2}+s_{i} \sum_{j=1}^{n} q_{j \neq i} .
$$

TABle 2: Estimation of the cost function coefficients by linear regression.

\begin{tabular}{lc}
\hline Intercept & 5.06 \\
\hline Milk & 0.0001412 \\
Milk $^{2}$ & $-5.683 \times 10^{-11}$ \\
$R^{2}$ & 0.90 \\
Adj. $R^{2}$ & 0.90 \\
Num. obs. & 1482 \\
\hline
\end{tabular}

And thus, each producer aims to maximize his profit $\pi_{i}$, while avoiding flooding the market with milk. In other words, the total milk production of the different competitors must be lower than the absorption capacity of the market.

\section{Nash-Cournot's Equilibrium}

We assume the existence of two representative companies such as

$$
\left\{\begin{array}{l}
c_{0,1}=\sum_{i=1}^{m} c_{0, i}, \\
c_{0,2}=\sum_{i=m+1}^{n} c_{0, i}, \\
c_{1,1}=\frac{1}{m} \sum_{i=1}^{m} c_{1, i} \\
c_{1,2}=\frac{1}{n-m} \sum_{i=m+1}^{n} c_{1, i}, \\
c_{2,1}=\frac{1}{m} \sum_{i=1}^{m} c_{2, i}, \\
c_{2,2}=\frac{1}{n-m} \sum_{i=m+1}^{n} c_{2, i},
\end{array}\right.
$$


with $m<n$ a number that subdivides the companies into two different categories in such a way that we only find two producers, representing the two main types of actors we have, namely, the 1 to $m$ are the small producers with a highcost function and the $m-n+1$ to $n$ are the main producers who have a comparative advantage in terms of cost and economy of scale and therefore can produce cheaper.

Each producer tries to maximize his profit while ensuring the optimal response to his competitor's production. We remind that we have a Nash equilibrium when each production strategy is optimal taking into consideration the strategies of its competitors. So a Nash equilibrium exists when there is no profit to be gained unilaterally from the strategy adopted by all the producers in competition. In other words, no producer will undertake a different action as long as the competition strategy is the same. This problem can be translated mathematically as follows.

The first producer needs to solve the following problem:

$$
\left(P_{1}\right) \begin{cases}\pi_{1}=<Q,-A Q>+<\alpha, Q>+\beta^{1}, \\ \text { Subject to } & \\ & q_{1}+q_{2} d_{0}, \\ & q_{1} 0 \\ & q_{2} \text { is given, }\end{cases}
$$

with

$$
A=\left(\begin{array}{cc}
-c_{2,1}+\frac{1}{d_{1}} & \frac{1}{2 d_{1}} \\
\frac{1}{2 d_{1}} & 0
\end{array}\right), \alpha=\left(\begin{array}{c}
\frac{d_{0}}{d_{1}}-c_{1,1} \\
s_{1}
\end{array}\right), \beta^{1}=-c_{0,1}
$$

while the second producer has to solve the problem

$$
\left(P_{2}\right)\left\{\begin{array}{l}
\pi_{2}=<Q,-B Q>+<\gamma, Q>+\beta^{2}, \\
\text { Subject to } \\
\\
q_{1}+q_{2} d_{0}, \\
\\
q_{2} 0 \\
\\
q_{1} \text { is given, }
\end{array}\right.
$$

with

$$
B=\left(\begin{array}{cc}
0 & \frac{1}{2 d_{1}} \\
\frac{1}{2 d_{1}} & -c_{2,2}+\frac{1}{d_{1}}
\end{array}\right), \gamma=\left(\begin{array}{c}
s_{2} \\
\frac{d_{0}}{d_{1}}-c_{1,2}
\end{array}\right), \beta^{2}=-c_{0,1} .
$$

We specify that the pair $\left(q_{1}, q_{2}\right)$ is called a Nash equilibrium if and only if $q_{1}$ is a solution of $\left(P_{1}\right)$ with given $q_{2}$, and $q_{2}$ is a solution of $\left(P_{2}\right)$ with given $q_{1}$.
TABLE 3: Characteristics of the Moroccan milk market to be simulated.

\begin{tabular}{ccccc}
\hline & $d_{0}$ & $d_{1}$ & $c_{1,1}$ & $c_{2,1}$ \\
\hline Value & $5,418,000,000$ & $470,571,428$ & 6 & $5 * 10^{-11}$ \\
\hline
\end{tabular}

To solve the Nash equilibrium problem, we use the Karush-Kuhn-Tucker essential conditions. These conditions applied to the problem $\left(P_{1}\right)$ and $\left(P_{2}\right)$ stipulate that if $q_{1}$ is a solution of $\left(P_{1}\right)$ and $q_{2}$ is a solution of $\left(P_{2}\right)$. As a result, we obtain the following system.

$\exists \lambda^{(1)}, u^{(1)}, v^{(1)}$, such as,

$$
\left\{\begin{array}{l}
2 A Q-\alpha+S \lambda^{(1)}-I^{T} u^{(1)}=0, \\
<\lambda^{(1)}, S^{T} Q-d_{0}>=<u^{(1)},-Q \geq 0, \\
S^{T} Q-d_{0}+v^{(1)}=0,
\end{array}\right.
$$

with

$$
S=\left(\begin{array}{l}
1 \\
1
\end{array}\right)
$$

then $<\lambda^{(1)},-v^{(1)} \geq 0$ and $<u^{(1)},-Q \geq 0$.

And $\exists \lambda^{(2)}, u^{(2)}, v^{(2)}$, such as

$$
\left\{\begin{array}{l}
2 B Q-\gamma+S \lambda^{(2)}-I u^{(2)}=0, \\
<\lambda^{(2)}, S^{T} Q-d_{0}>=<u^{(2)},-Q \geq 0, \\
S^{T} Q-d_{0}+v^{(2)}=0,
\end{array}\right.
$$

then $<\lambda^{(2)},-v^{(2)} \geq 0$ and $<u^{(2)},-Q \geq 0$

To maintain price positivity, it is assumed that $v^{(i)}>0$; therefore, $\lambda^{(i)}=0$ for all $i=1,2$. So,

$$
\begin{cases}u^{(1)}=2 A Q-\alpha, & \\ u^{(2)}=2 B Q-\gamma, & \text { For all } i=1,2, \\ v^{(i)}=d_{0}-S^{T} Q, & \text { For all } i=1,2, \\ <u^{(i)}, Q \geq 0, & \end{cases}
$$

therefore,

$$
\left(\begin{array}{c}
u^{(1)} \\
u^{(2)} \\
v^{(1)}
\end{array}\right)=\left(\begin{array}{ccc}
2 A & 0 & S \\
0 & 2 B & S \\
-S^{T} & 0 & 1
\end{array}\right)\left(\begin{array}{l}
Q \\
Q \\
0
\end{array}\right)+\left(\begin{array}{c}
-\alpha \\
-\gamma \\
d_{0}
\end{array}\right) .
$$




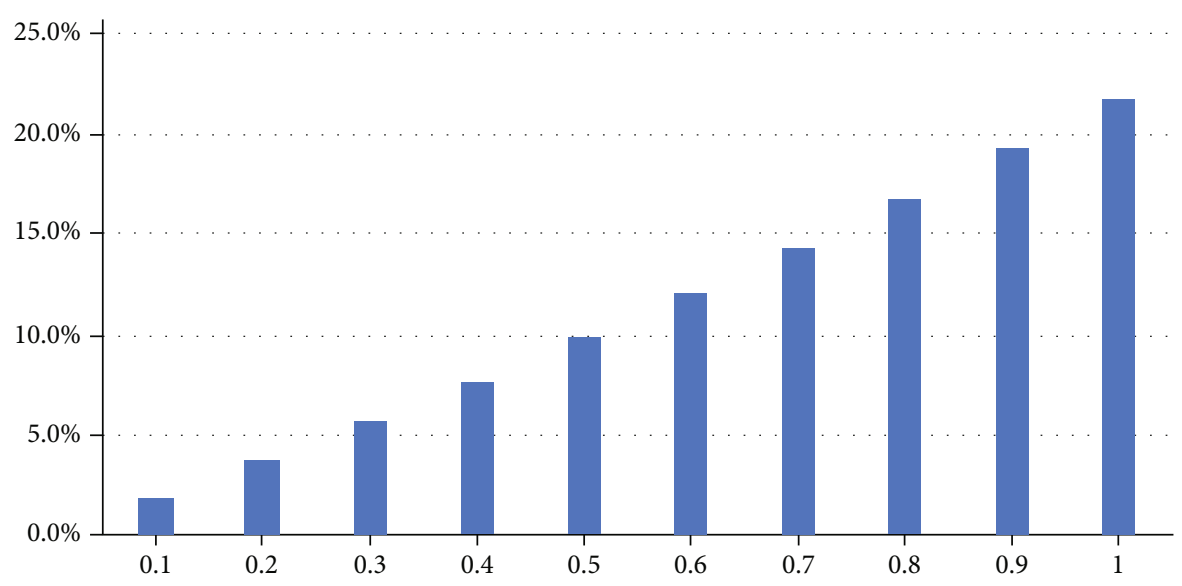

FIGURE 6: Market share of small producers based on the state subsidy.

Let us denote by

$Z=\left(\begin{array}{l}Q \\ Q \\ 0\end{array}\right), W=\left(\begin{array}{l}u^{(1)} \\ u^{(2)} \\ v^{(1)}\end{array}\right), M=\left(\begin{array}{ccc}2 A & 0 & S \\ 0 & 2 B & S \\ -S^{T} & 0 & 1\end{array}\right), b\left(\begin{array}{c}-\alpha \\ -\gamma \\ d_{0}\end{array}\right)$,

then our problem is equivalent to the linear complementarity problem, $\operatorname{LCP}(M, b)$.

This is the same as finding the vectors $Z, W \in \mathbb{R}^{5}$ such that $W=M Z+b 0, Z, W 0$ and $Z^{T} W=0$. It is easy to show that the matrix $M$ is a $P$-matrix; therefore, the linear complementarity problem admits one and only one solution. This solution is given by

$$
\left(\begin{array}{l}
q_{1} \\
q_{2}
\end{array}\right)=\left(\begin{array}{c}
d_{1} s_{1} \\
d_{0}-d_{1}\left(\left(2 s_{1}+c_{11}\right)-2 d_{1} s_{1} c_{21}\right)
\end{array}\right) .
$$

According to the values obtained through the estimation of the cost function thanks to the linear regression, the value of $c_{21}$ is so small that the term $2 d_{1} s_{1} c_{21}$ is negligible, so the positivity condition of $q_{2}$ is $2 s_{1}+c_{11}<d_{0} / d_{1}$ which should be true as long as the value of government subsidies is not too high. Another interesting result is that the second company that we will consider as the major milk producer has to take into consideration the characteristics of the small producer during its production, independently of its own costs, which is logical since they are negligible compared to those of the small producer.

\section{Simulation and Discussion}

According to Fimalait (the Moroccan interprofessional federation of milk), the landscape of milk producers in Morocco is distributed as follows: first, Central Danone with a $55 \%$ market share, then Copag with $20 \%$ of the market, Safilait with 7\%, Colainord (5.8\%), Best Milk (4.4\%), and Colaimo $(3.2 \%)$ are the followers. The remaining shares are divided between small producers or import and distribu- tion companies (4.6\%), so it is easy to assume that the market share of small milk producers is less than 3\% (see [39]).

The current consumption of milk in Morocco is on average 59 liters per person, and according to the WHO, the Moroccan consumption remains below the world average. In fact, according to the latest consumption survey in Morocco conducted by the HCP [40], the wealthiest $10 \%$ of Moroccans consume 150.5 liters of milk per year. It is assumed that for Morocco, the value of the $d_{0}$ is when the 36 million Moroccans will consume 150.5 liters instead of 56. Moreover, according to this hypothesis and the fact that the current price of milk is $7 \mathrm{MAD}$, we can deduce the value of $d_{1}$ which will thus be $470,571,428$. A value of $d_{1}$ which so important is not surprising especially when we know that there was a total boycott of the main seller of milk in Morocco in 2018 following the rise in prices.

According to [41], the average cost of milk production among small producers in Morocco is 4.21 MAD per liter; moreover, these small producers must resort to intermediaries for packaging and delivery of milk which increases the cost to $6 \mathrm{MAD}$ per liter. So from these elements, we can take the necessary values for our simulation as follows, in Table 3.

In Figure 6, we can see the evolution of the market shares of small producers as a function of the state subsidy $s_{1}$.

We can easily see that if the state subsidizes small producers at the level of 0.5 MAD for each liter produced by the competition, we can triple the market share of small producers, and therefore, they can have a share of $9.9 \%$ of the overall production. It should be noted that this equilibrium is close to the current state of the economy; in fact, the price per liter will be 6.47 MAD vs. 7 MAD currently, but average annual per capita consumption will improve to 68.33 liters vs. 59 according to the WHO.

Nevertheless, the large margin of the intermediaries is not in the interest of the consumer. We can see that the unit production costs of the small producer directly impact the global production. Therefore, it would be interesting to see the evolution of the state of equilibrium if we go from a unit cost of 6 to 4 which can be achieved by helping small producers to avoid relying on intermediaries. We can see in Figure 7 the evolution of the shares according to the subsidy with the decrease of the unit costs. 


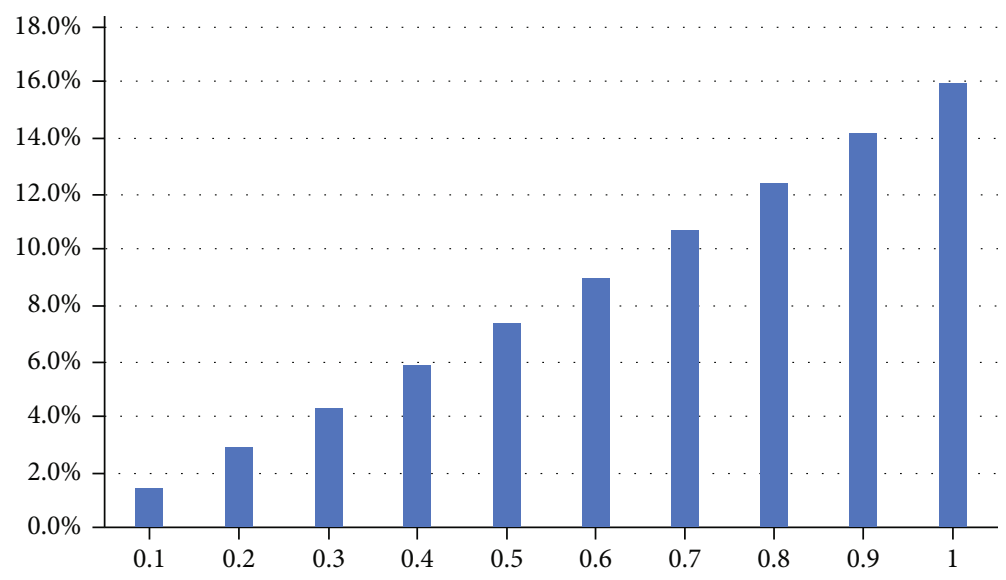

FIgURE 7: Market share of small producers as a function of the state subsidy with a reduction in costs.

It can be seen that the drop in unit cost will lead to an overall drop in the market share of small businesses. Indeed with a subsidy of $0.5 \mathrm{MAD}$ for each liter produced by the competition will result in a market share of $7.1 \%$ against $9.9 \%$ before. Nevertheless, the liter price is $4.47 \mathrm{MAD}$, and the average annual consumption of milk increases to 94 liters per capita; therefore, we obtain a considerable improvement over the first simulation.

\section{Conclusion}

We calculated in this work the milk production that maximizes the profit of both producers while avoiding a flood of the market by using Nash's equilibrium problem. We estimated statistically the different components of the profit function and, finally, performed two simulations to illustrate our point. These two simulations are both rich in results, but one question remains unanswered. How can the state finance this subsidy, whether it is the subsidy to the competition or the reduction of the unit cost? We can suppose that this financing can be done through a tax that draws from the comparative advantage of the large firm, which gives it an important increasing return on scale. In fact, a levy on the reduction of costs following these advantages will be more than enough to finance the subsidy without taking the main producers' advantage, especially when it is a question of large production volume, because the term used to describe these advantages is quadratic, whereas the subsidy is not.

In terms of improvement, as we have seen, this equilibrium calculation increases the production of small businesses but does not take into consideration the well-being of the consumer; therefore, we could add a new player who would represent the consumers, and we would have to maximize his utility. On the other hand, to consider that the two products are perfectly homogeneous is generally unrealistic; there will always be distinctions between the different products and, therefore, distinctions in their prices. Another important point is that we cannot assume that the consumer's behavior will be translated in a linear way with respect to the variation of the price; in fact, a variation of the price can in itself lead to a variation of $d_{1}$ which is, let us recall, a marginal effect. In addition, the consumer demand function does not depend on the price of a single good. Indeed, the latter depends on all the goods that make up the consumer's basket, so it would be useful to recalculate this equilibrium but taking into account a multitude of products. Finally, it would also be interesting to recalculate this equilibrium by taking into consideration all the economic actors producing milk on the Moroccan market, i.e., the six main economic actors and a company representing the small breeders. Such an approach would allow us to evaluate with precision the evolution of the different market shares as well as its impact on each producer.

\section{Data Availability}

No data were used to support this study.

\section{Conflicts of Interest}

The authors report no conflicts of interest. The authors alone are responsible for the content and writing of the paper.

\section{References}

[1] "Employment by branch of activity of the employed labor force at national level, Haut-Commissariat au Plan du Maroc," August 2021, https://www.hcp.ma/Emploi-par-branche-dactivite-de-la-population-active-occupee-au-niveau-national_ a155.html.

[2] "Emploi par branche d'activité de la population active occupée au niveau national, Haut-Commissariat au Plan du Maroc," August 2021, https://www.hcp.ma/Comptes-nationaux_r126 .html.

[3] “Les Aides Financières de l'État pour lâ $€$ encouragement des investissements agricoles, Haut-Commissariat au Plan du Maroc," August 2021, http://www.abhatoo.net.ma/maalamatextuelle/developpement-economique-et-social/ developpement-economique/agriculture/financement-de-1agriculture/les-aides-financieres-de-l-etat-pour-lencouragement-des-investissements-agricoles. 
[4] "Principales Réalisations du Plan Maroc Vert, Agence pour le DÃ@ veloppement Agricole," August 2021, https://www.ada .gov.ma/fr/principales-realisations-du-plan-maroc-vert.

[5] "Le secteur agricole marocain: Tendances structurelles, enjeux et perspectives de développement, Ministère de l'Économie et des Finances," August 2021, https://www.finances.gov.ma/ Publication/depf/2019/Le\%20secteur\%20agricole\%20marocain .pdf.

[6] "Agriculture, forestry, and fishing, value added (constant 2010 US\$) - Morocco, World Bank," August 2021, https:// data.worldbank.org/indicator/NV.AGR.TOTL.KD?locations= MA.

[7] F. Laitière, "Ministère de l'Agriculture, de la Pêche Maritime, du Développement Rurale et des Eaux et Forêts," August 2021, https://www.agriculture.gov.ma/fr/filiere/lait.

[8] “La filière laitère au Maroc, Agrimaroc," August 2021, https:// www.agrimaroc.ma/filiere-laitiere-maroc/.

[9] A. Harri, J. G. Maples, J. M. Riley, and J. B. Tack, "Firm decision making under both input and output price uncertainty," Journal of Agricultural and Resource Economics, vol. 45, pp. 549-570, 2020.

[10] E. J. Levin, Y. Ma, and R. E. Wright, "Profit maximization in a multi-product firm with impatient customers," Journal of the Operational Research Society, vol. 55, no. 3, pp. 211-218, 2004.

[11] H. R. Varian, Microeconomic Analysis, Norton, New York, 1992.

[12] J. Abbasov, "A new simple algorithm for solution of optimization problems," Journal of International Studies, vol. 11, no. 2, pp. 95-103, 2018.

[13] Z. A. Khan, "Profit maximisation as an objective of a firm - a robust perspective," International Journal of Research in Finance and Marketing, vol. 7, pp. 217-219, 2017.

[14] B. Zhou, H. Sun, and Jiangsu Provincial Key Laboratory for NSLSCS, School of Mathematical Sciences, Nanjing Normal University, Nanjing, 210023, China, "Two-stage stochastic variational inequalities for Cournot-Nash equilibrium with risk-averse players under uncertainty," Numerical Algebra, Control \& Optimization, vol. 10, no. 4, pp. 521-535, 2020.

[15] P. I. Helgesen and A. Tomasgard, "An equilibrium market power model for power markets and tradable green certificates, including Kirchhoff's laws and Nash-Cournot competition," Energy Economics, vol. 70, pp. 270-288, 2018.

[16] Q. Chen, P. Zou, C. Wu et al., "A Nash-Cournot approach to assessing flexible ramping products," Applied Energy, vol. 206, pp. 42-50, 2017.

[17] R. Hannesson, "The Nash-Cournot approach to shared fish stocks: an empirical investigation," Marine Policy, vol. 118, p. $103978,2020$.

[18] Y. I. Suleiman, H. Ur Rehman, A. Gibali, and P. Kumam, "A self-adaptive extragradient-CQ method for a class of bilevel split equilibrium problem with application to Nash Cournot oligopolistic electricity market models," Computational and Applied Mathematics, vol. 39, no. 4, pp. 1-20, 2020.

[19] Z. Xu, L. Yao, X. Zhou, M. Moudi, and L. Zhang, "Optimal irrigation for sustainable development considering water rights transaction: a Stackelberg-Nash-Cournot equilibrium model," Journal of Hydrology, vol. 575, pp. 628-637, 2019.

[20] K. G. Murty, "On the number of solutions to the complementarity problem and spanning properties of complementary cones," Linear Algebra and its Applications, vol. 5, no. 1, pp. 65-108, 1972.
[21] M. Katta, Principal Pivoting Methods for LCP, Department of Industrial and Operations Engineering, University of Michigan, 1997.

[22] R. W. Cottle, J. S. Pang, and R. E. Stone, The Linear Complementarity Problem, Academic Press, New York, 1992.

[23] H. El Bouanani, Y. El Foutayeni, and M. Khaladi, "A new method for solving non-linear complementarity problems," International Journal of Nonlinear Science, vol. 19, pp. 81-90, 2015.

[24] Y. El Foutayeni, H. El Bouanani, and M. Khaladi, "The linear complementarity problem and a method to find all its solutions," Inf Scientific Computation, vol. 3, pp. 1-5, 2015.

[25] Y. el Foutayeni, H. el Bouanani, and M. Khaladi, “An (m+1)step iterative method of convergence order $(m+2)$ for linear complementarity problems," Journal of Applied Mathematics and Computing, vol. 54, no. 1-2, pp. 229-242, 2017.

[26] Y. El Foutayni and M. Khaladi, "A new interior point method for linear complementarity problem," App The Mathematical Scientist, vol. 4, pp. 3289-3306, 2010.

[27] J. S. Pang, Complementarity Problems, Handbook of global optimization. Springer, Boston, MA, 1995.

[28] J. Wang, S. Hu, and Z. H. Huang, "Solution sets of quadratic complementarity problems," Journal of Optimization Theory and Applications, vol. 176, no. 1, pp. 120-136, 2018.

[29] V. T. Hieu, Y. Wei, and J. C. Yao, "Notes on the optimization problems corresponding to polynomial complementarity problems," Journal of Optimization Theory and Applications, vol. 184, no. 2, pp. 687-695, 2020.

[30] M. T. Srari, M. T. Benyoucef, and K. Kraiem, "The dairy chains in North Africa (Algeria, Morocco and Tunisia): from self sufficiency options to food dependency?," Springerplus, vol. 2, pp. 1-13, 2013.

[31] M. Baccar, A. Bouaziz, P. Dugué, and P. Y. Le Gal, "Shared environment, diversity of pathways: dynamics of family farming in the Saiis plain (Morocco)," Regional environmental change., vol. 17, no. 3, pp. 739-751, 2017.

[32] M. T. Sraïri, M. el Jaouhari, A. Saydi, M. Kuper, and P. Y. le Gal, "Supporting small-scale dairy farmers in increasing milk production: evidence from Morocco," Tropical Animal Health and Production, vol. 43, no. 1, pp. 41-49, 2011.

[33] T. Kawaguchi, N. Suzuki, and H. M. Kaiser, "A spatial equilibrium model for imperfectly competitive milk markets," American Journal of Agricultural Economics, vol. 79, no. 3, pp. 851859, 1997.

[34] M. Msaddak, J. Ben-Nasr, and L. Zaibet, "Resolving recurrent imperfections in the dairy production using gaming simulation," New Medit, vol. 18, no. 4, pp. 35-50, 2019.

[35] M. Msaddak, J. Ben-Nasr, and L. Zaibet, "Dynamics of trust and cooperation in the dairy value chain: a game simulation approach," Journal of International Food \& Agribusiness Marketing, vol. 33, no. 4, pp. 353-373, 2021.

[36] "Weekly dairy product prices," Kaggle. August 2021, https:// www.kaggle.com/sohier/weekly-dairy-product-prices.

[37] "Spanish dairy farm production," August 2021, http://people .stern.nyu.edu/wgreene/Econometrics/PanelDataSets.htm.

[38] E. G. Alvarez, M. F. MontaZo, R. A. Ware, and R. A. Zinn, "Influence of dietary forage level on digestive function and growth performance in cattle fed steam-flaked corn-based growing-finishing diets," Journal of Animal and Veterinary Advances, vol. 3, pp. 503-509, 2004. 
[39] "La filière laitière au maroc," August 2021, https://www.fellahtrade.com/fr/actualites-maroc/article?id=861.

[40] "Présentation des résultats de l'Enquête Nationale sur la Consommation et les Dépenses des Ménages," August 2021, https://www.hcp.ma/downloads/Enquete-Nationale-sur-laConsommation-et-les-Depenses-des-Menages_t21181.html.

[41] M. T. Srari, "Le prix de revient du lait au Maroc et ses implications pour l'avenir de l'élevage bovin," Alternatives Rurales, vol. 1, pp. 54-64, 2014. 